Article

\title{
The Anime Connection. Early Euro-Japanese Co-Productions and the Animesque: Form, Rhythm, Design
}

\author{
José Andrés Santiago Iglesias $\mathbb{D}$
}

Fine Arts Faculty, Drawing Department, University of Vigo, 36002 Pontevedra, Spain; jsantiago@me.com

Received: 3 July 2018; Accepted: 28 September 2018; Published: 5 October 2018

check for updates

\begin{abstract}
After European audiences had first contact with anime in the late 1970s, animated co-productions between domestic producers and Japanese studios emerged in the early 1980s, playing a lead role in standardizing anime aesthetics and hence contributing to the broader development of anime in Spain and other major European markets. These pioneering co-productions fostered the arrival of Japanese studios to the European broadcasting scene. However, its real impact on the popularization of anime is subject to debate. Appealing to a European audience, these series lacked some of the most recognizable features associated with anime as a larger medium. Nonetheless, in some of these animated productions there was an underlying animesque flair in the shape of conventionalized elements, character design, facial expressions, rhythm, camera action and tropes. Neither entirely domestic nor fully Japanese, these hybrid productions set up a 'bridge' between European and American animated visual language and anime mainstream features, thereby shaping the collective idea of what anime is for the first generation of viewers in Spain and Europe.
\end{abstract}

Keywords: anime; animesque; co-productions

\section{Introduction}

In the early 1980s the Spanish anime scene was quite different from other major European markets-mostly Italy and France-due to the disparate pace of the liberalization of TV frequencies and the subsequent arrival of several (Japanese) anime productions to those markets. In contrast, Euro-Japanese co-productions gathered momentum, becoming immensely popular among Spanish children's audiences. I believe these early co-productions or hybrid-productions-seeming neither entirely domestic nor fully Japanese — set up a 'bridge' of sorts between European and American animated visual language and mainstream anime features, thereby shaping the collective idea of what anime is for the first generation of viewers in Spain and in Europe. Thus, throughout this paper I will try to highlight the paramount role of Euro-Japanese animated co-productions in the popularization of anime aesthetics and how these pioneering co-productions fostered the arrival of Japanese studios and anime licenses to the European broadcasting scene.

I will not address Euro-Japanese animated co-productions focusing on market and productionrelated issues; rather, I will approach from a material perspective, leaning on rhythm, movement, cinematography, design and aesthetics. In order to do so, I will mostly rely on animated series from the first half of the 1980s rather than more recent productions. To this end, I will basically structure this paper in three major parts: firstly, I will briefly address when and how co-productions arose in Spain; secondly, I will emphasize the role played by the licensing company and producer BRB International within the Spanish scenario previously described; finally, I will try to highlight some similarities and differences between anime and these Euro-Japanese animated co-productions and 
address some of those particularities, focusing on some prominent examples that have a stronger 'anime feel'-including several Spanish BRB International and Nippon Animation co-productions.

\section{The Rise of Euro-Japanese Animated Co-Productions}

When we address the Spanish anime scene within a larger European frame, we should begin in the late 1970s. The anime fever began in Spain with Mazinger $Z^{1}$ and Heidi ${ }^{2}$, the dynamic that arose between both animated productions, and what they meant for viewers and anime itself as a fulfilled medium. Despite the first attempts to successfully distribute and commercialize Japanese animation in the late 1960s and early 1970s, it was not until Heidi's arrival that anime started to gain the attention of audiences as a standalone medium in Spain. Comprising 52 episodes, Heidi was produced by Zuiyo Enterprises, directed by Isao Takahata and casted Hayao Miyazaki as artistic director of the show. Considered the very first of several series produced under the common label Meisaku (literal meaning "theater masterpieces"), it was a major success among children and adults alike. However, Heidi's unprecedented success was also shaped by the broadcast of Mazinger $Z$ in the following years.

Spain was the first western country in which Mazinger $Z$ was broadcast-rather than France or Italy, two countries in which a similar Mazinger phenomenon never took place ${ }^{3}$. What ultimately makes Mazinger $Z$ a unique case study is its legacy, which greatly differs from that of other anime series broadcast in Spain during that decade and which was closely related to the political, social and educational criticism that arose after the late 1970s. Considered violent and harmful for children's education, only 32 of the 92 chapters from the original series were finally aired.

From 1978, several articles appeared complaining about Mazinger $Z$ and its negative influence on children ${ }^{4}$. The show was described as aggressive, violent and full of sexist connotations surrounding the character of Sayaka (Ortega 1978, p. 26) and her female robot. While some censorship was already applied to the series in Spain, it was still considered by many conservative groups as sexist and harmful for children. Mazinger was also described as simple manichaeism ${ }^{5}$ and criticized for its simple, child-friendly script: the classical figures of good versus evil, fighting to the death. Ultimately it was addressed as "a mythification of the American technicism deeply established in Japan as a colony" or "a glorification of violence" (Fernández 1978, pp. 25-26). ${ }^{6}$

For many years, researchers suggested a connection between the premature cancellation of the broadcast of Mazinger on $\mathrm{TVE}^{7}$ and the complaints led by politicians, educators, newspapers and parental organizations protesting the explicit violence and the implied aggression in some of the

1 Toei Animation 1972. Based on the eponymous manga by Gō Nagai. Entitled in Castilian Spanish as Mazinger El Robot de las Estrellas, Mazinger $Z$ was first screened on TVE on 4 March 1978.

2 Arupusu no Shōjo Haiji, Nippon Animation 1974. Heidi first aired in Spain on 2 May 1975, on a children's TV program (Un globo, dos globos, tres globos) on the national public TV channel TVE (Televisión Española).

3 Instead, UFO Robot Grendizer is considered an equally huge success both in Italy and France. Known in both countries as 'Goldrake' or Goldorak, UFO Robot Grendizer is an anime produced by Toei Animation, part of the Mazinger franchise originally created by Gō Nagai. UFO Robot Grendizer was broadcast in Japan from 1975 to 1977. For further information on the topic, I would refer Marco Pellitteri's in-depth analysis (Pellitteri 2008).

4 "La Televisión como escuela de Violencia" (TV as a school of violence) by Juan Manuel Ortega and published in the conservative newspaper $A B C$ in 1978. 15 October 1978, p. 118, depicts a picture of Mazinger $Z$ and quotes a survey carried out by CBS, which states: "kids who watch violent series ultimately behave violently."

5 Jesús Romero, in a radio interview (21 March 2014), suggested that many complaints were not solely pointed at the violence but rather focused on the lack of a more sophisticated plot, as with Romero in: Las tardes del Ciudadano García-'Mazinger Z', un hito generacional (RTVE 2014). Romero is also the author of the divulgate book entitled Mazinger. Planeador abajo. Palma de Mallorca: Dolmen.

6 "In the foreground stand the actual main characters, the monsters fighting each other: on one side Mazinger $\mathrm{Z}$, and on the other side a long series of horrid machines of destruction, identified by different acronyms. This is the main pattern of the movie. In the background, like underrated beings in this world, are the men who pilot the robots: Kōji, a classical cliché of the "gutsy youth» of overdeveloped countries; the wise scientist who loves peace; the hermaphrodite Baron Ashler and, the apex of evil, Doctor Hell. All of them away from the real fight, in a society in which everything works through a button." (Fernández 1978, p. 25). In the original article Kōji is referred to as 'Soji' and Baron Ashler/Ashura (アシュラ) as Baron Asler. For consistency, translation of the original quote follows the original character's names.

7 Acronym of Televisión Española, the national state-owned television broadcaster in Spain. 
dialogues and situations. However, other researchers (Romero 2014) recently pointed out that Toei did not circulate the full 96-episode series in Europe but issued an adapted 'international edition,' consisting of approximately a third of the original anime. According to Romero, Toei sold the rights to a short, highly edited version consisting of those 33 episodes, more similar to the length and number of episodes of the American series to which European broadcasters were accustomed (Querol 2011). Either way, TVE broadcast only up to episode 56, in which the superalloy $Z$ is stolen by the evil minions of Dr. Hell, leaving the viewers with a bittersweet feeling and a general sensation of confusion and unfinished business (Sanz-Arranz 2011). While it is true that after harsh criticism from parental associations and newspapers alike the broadcast went into hiatus for nearly three months, Mazinger $\mathrm{Z}$ was scheduled to return in early 1979 , and the remaining five episodes were finally aired. Years later it was rescheduled via different national broadcasters, but it never reached the wide exposure of hits like Heidi or Marco, which were screened for years on different TV channels after their debut.

From this point onwards, many parents and politicians harshly disapproved of Japanese productions, complaining about the violence often depicted in anime (Montero 2012, p. 48). Moreover, the fact that many of the early anime films screened in Spain via adult film retail and distribution companies (as opposed to the usual children's distributors) led to the idea than anime as a whole was not suitable for children ${ }^{8}$. Paradoxically, many of the same people praised the 'family-friendly' values as shown in Nippon Animation's Heidi and Marco and many other series that comprise the Meisaku collection ${ }^{9}$, in contrast with the dystopian future of war and violence portrayed in Mazinger Z. Consequently, this duality reinforced the idea that Heidi was not a Japanese anime but rather a Spanish or European production. Nonetheless, we could conclude that while the overall success of Heidi was greater than Mazinger's_appealing to a larger substratum of Spanish viewers-the overall impact of Mazinger $Z$ on the Spanish anime market was far more significant. Within the Spanish anime scene, Mazinger $Z$ altered the concept of animation for children and adults alike, shaking generational barriers for this medium.

It was not until the early 1990s that the anime industry finally blossomed in Spain. Actually, the development of the anime industry in Spain in the late 1970s and 1980s and its boom in the early 1990s mimics its progression in France and Italy, the latter playing a major role in the import and retail of many Japanese series in the early 1980s (Pellitteri 2010). However, I would argue that the different pacing in the timeline between the anime boom in Spain and other European countries ultimately defines the specific Spanish scenario ${ }^{10}$. Between 1978 and 1983 more than 183 anime series were broadcast on several Italian channels (Moliné 2002, p. 68) ${ }^{11}$. Meanwhile, the lack of private broadcasters in Spain due to the delay of the liberalization of TV frequencies led to a wholly different scenario, providing a new opportunity for Euro-Japanese co-productions to thrive.

There was a lag of approximately 5 to 10 years between the Italian and French anime boom in the 1980s and the one that took place in Spain in the early 1990s as a result of the liberalization of TV frequencies and the arrival of Dragon Ball. Although the Spanish model is similar to most European countries, the timing of events differed greatly and did not overlap with the French or the Italian scene. Ultimately, different timing led to circumstances specific to each nation. The development of Euro-Japanese animated co-productions had a major impact in the Spanish market precisely due to the delay in the arrival of relevant anime productions compared to events in Italy and France as a result of the liberalization of TV frequencies. In that regard, two factors played a major role: the lack of private broadcasters apart from the state-run TVE channels, therefore leading to a lesser demand for

8 I am grateful to my third blind reviewer for highlighting this connection.

9 Nippon Animation's Meisaku collection (lit. meaning “theater masterpieces") involved several titles depicting the same family-friendly histories, adapting or clearly inspired by some European literary classics meant for children. On 8 January 1977, two years after Heidi's premiere, Marco, de los Apeninos a los Andes (Haha wo tazunete sanzenri, 1976) was first broadcast in TVE, quickly followed by other animated productions such as El perro de Flandes (Furandâsu no inu, 1975).

10 For further discussion on the Spanish anime timeframe between 1975 and 1990, see Santiago (2017).

11 Moliné refers to the source: Eureka 11-12, November-December 1983, p. 5. 
anime series; and the involvement of BRB International, which pioneered the European co-production market—ahead of other audiovisual corporations from more prominent markets—by popularizing Spanish-Japanese co-productions across the European scene. Although I will be addressing the role of Euro-Japanese co-productions within the Spanish anime timeline, I sincerely believe that the main findings and observations regarding these animated series could be extrapolated to other major European markets.

\section{The Leading Role of BRB International}

Between the early arrival of Mazinger $Z$ in the mid-1970s and the anime boom that took place in the 1990s, the Spanish anime scene was very different from the thriving scenario described in Italy and France. A hiatus of sorts took place between the Meisaku era and the Dragon Ball phenomenon yet to come. However, this anime rupture throughout the 1980s favored the development and arrival of several Euro-Japanese animated co-productions-and specifically Hispanic-Japanese co-productions-leading to what now can be only addressed as a 'golden age' for these hybrid products.

Following the Mazinger controversy, politicians and parental associations responded by enacting several codes of good practice, with general guidelines regarding the depiction of violence on children's TV shows. This political response against action-anime also fostered domestic productions. Nevertheless, the Spanish animation industry lacked the resources and time to start producing from scratch. Accordingly, several co-productions emerged in the late 1970s and early 1980s, many of them between Spanish producers and Japanese studios, the latter being responsible for technical development. In this regard, the Spanish media company BRB International, which had already played a key role in the arrival and rise of anime in Spain, became one of the most prominent agents. Having licensed Mazinger $\mathrm{Z}$ in the first place, BRB International began to produce its own animated series, most of them in partnership with Nippon Animation ${ }^{12}$ alongside other Asian animation studios ${ }^{13}$.

Founded in 1972, BRB International mainly focused on production, distribution and broadcasting licenses. BRB International started as a content distributor of American and European productions from Hannah-Barbera and Warner Bros., and it was responsible for the arrival of series such as Tom $\mathcal{E}$ Jerry, The Muppets and The Pink Panther to Spain. In 1975, BRB International commercialized Mazinger Z, and afterwards started to distribute Euro-Japanese co-productions such as Maya the Honey Bee ${ }^{14}$,Vicky the Viking ${ }^{15}$, The Big Bear of Tallac ${ }^{16}$ or Bannertail ${ }^{17}$. However, beginning in 1980, BRB International also started producing its own animated material, achieving three noticeable audience hits in partnership with Nippon Animation, beginning a long and successful relationship with this Japanese studio: Ruy, Little Cid, Dogtanian and the Three Muskehounds and Around the World with Willy Fog ${ }^{18}$. Actually, these BRB International productions may as well be the first collaboration between media industries in Spain and Japan. BRB's founder, Claudio Biern Boyd, was involved in many of these early projects, being

12 Ruy, Pequeño Cid (Ritoru Eru Shido no bōken, 1980), D'Artacán y los tres mosqueperros (Wanwan Sanjushi, 1981) and La vuelta al mundo de Willy Fog (Anime Hachijūnichikan Sekai Isshū, 1983).

13 David el Gnomo (The World of David the Gnome)—produced in 1985 in partnership with a Taiwanese studio-being the most remarkable example.

14 Mitsubachi Maya no bōken, Nippon Animation, 1975.

15 Chiisana Baikingu Bikke, Nippon Animation, 1972.

16 Seton Dôbutsuki Kuma no ko Jakkī, 1977.

17 Banner y Flappy (Seton Dôbutsuki Risu no bannâ; German: Puschel, das Eichhorn; and English: Bannertail: The Story of Gray Squirrel) is a German-Japanese animated series. It is based on the tales by Ernest Thompson Seton and co-produced by ZDF (Zweites Deutsches Fernsehen, a German public TV broadcaster) and Nippon Animation. It premiered on April 7th, 1979. It first aired between 1979 and 1980 in Spain.

18 Ruy, Pequeño Cid (Ritoru Eru Shido no bōken, 1980) was a co-production between BRB International and Nippon Animation, also with the partnership of TVE (Televisión Española, de major public TV channel in Spain). Dogtanian (Wanwan Sanjushi, 1981) was produced by BRB Internacional and Nippon Animation. Around the World with Willy Fog (Anime Hachijünichikan Sekai Isshū, 1983) was produced by BRB Internacional and animated by Nippon Animation and TV Asahi, in partnership with TVE (Televisión Española). 
responsible for the concept and acting several times as both scriptwriter and character designer. Back in 1984, BRB International's sales VP stated: “We are currently producing a 26-segment animated series a year. Creation of the characters, script, storyboard, MEE, dubbing and postproduction are done in Spain, but the actual animation is handled in Japan, releasing one segment a week. Over there we can complete the whole series in six months, whereas in Spain it would probably take four years."19

However, the fever did not last. A few years later and after several popular hits, the enthusiasm for co-productions declined, and the initial will of Spanish broadcasters to produce their own children's content rapidly faded ${ }^{20}$. In this regard, we can highlight two decisive factors in the decline of Hispanic-Japanese animated co-productions: production budgets and the liberalization of TV broadcasting frequencies. By the end of the 1980s, it was far cheaper to buy anime series from the Japanese producers and European licensors and rights-holders than investing a large amount of money in producing similar proprietary content. Concurrently, the emergence of new TV private channels (Antena 3 and Tele 5, with particular relevance for the latter, owned by the Italian conglomerate Finninvest) fostered the arrival of imported anime series from its partner networks in Italy and France. Anime was cheaper, it was easily produced, and they only needed to import it from neighboring nations. The adaptation and dubbing process (from Italian or French dubbing, instead of the original Japanese language, in the early years) was easier. In addition, the success of some mainstream titles in those markets was a strong endorsement, becoming a hit among the audience, reinforcing and giving priority to these series over domestic productions.

\section{Euro-Japanese Co-Productions and the Animesque}

There is little doubt that these co-productions opened the Spanish broadcasting market to Japanese studios and some anime licenses. However, its real impact on anime's future arrival and further boom still remains a subject of debate. The fact that these productions allowed a deeper partnership with Japanese license companies is undeniable. Nonetheless, for an European audience the lack of iconic markers that many fans nowadays recognize as part of the larger 'anime form' led many of them to think that while these series might be Japanese (or at least made in Japan), they were ultimately not anime. Euro-Japanese co-productions are usually acknowledged as a hybrid of sorts, an in-between not entirely western and not fully Japanese. Notwithstanding, for the scope of this article the relevant issue does not lie within the label (whether it is anime or not) but in the animesque ${ }^{21}$ within these animated series-especially now when many Japanese studios outsource their own productions to other companies all over southeast Asia, and anime itself has problems balancing its identity as a Japanese cultural artefact and its distinctly transnational scope (Suan 2017).

Thus far, co-productions have been seen as a rupture in the anime scene of the 1980s by fandom and researchers alike (Montero 2012), and ultimately as a means to strengthen the European animation and promote domestic productions. However, rather than addressing the differences, we should focus

19 Maria Aragon (BRB International's sales VP) in Variety (1984, p. 206).

20 This fact might eventually bring up some questions in regards to the popularity and continuity of these hybrid co-productions. Even though one could argue that the hybridization did not generate a sustained audience and was superseded by Japanese anime products, I ultimately believe that it was not a problem of critical mass but rather of budget: Japanese anime was cheaper than Euro-Japanese co-productions, thus leading to a market shift. Notwithstanding, the aforementioned BRB co-productions were very successful at the time; and in a similar light, today's anime-style US productions are also quite successful among an international audience.

21 I am using animesque in the same way as Suan does, who derives the word from 'the mangaesque', coined by Jaqueline Berndt. Mangaesque, as she describes is: "what passes as 'typically manga' (or typically anime) among regular media users... in the sense of manga-like or typically manga, which is, of course, no established scholarly term, yet it allows to draw attention to practically relevant popular discourses on the one hand and on the other to critically informed, theoretical reflections on what may, or may not, be expected from manga (and anime)" (Berndt 2012).

Therefore, in this paper animesque broadly refers to "anime style". Thus, animesque productions are those identified as anime by fans - even if these productions are not necessarily anime-or use formal and narrative elements that are traditionally linked with Japanese anime productions. In this paper, the animesque concept is useful to lessen the weight of the nihonjinron discourse and to focus the debate on the formal, narrative and design aspects that ultimately define this medium. 
on the similarities: I believe these early co-productions share core aspects which, in the mid-eighties TV scene, helped to build 'bridges' and shared traits with the anime series yet to come.

Among the several Euro-Japanese co-productions developed in the 1980s, there are noticeable differences between these various series regarding the degree of involvement of the Japanese studios. In some cases, the entire creative process was developed in Europe by different domestic studios, leaving only the production role to the Japanese counterparts; occasionally there was a real partnership, with teams on both sides equally contributing to the final product; and in some cases there was major Japanese leadership, while the European producer was solely responsible for financial control, outsourcing all the creative aspects of the project to the Japanese studio. Thus, a thorough classification would be truly difficult for the scope of this paper, but nevertheless remains an interesting topic to explore more deeply, studying how it affects its animesque dimension. However, there are shared traits that broadly apply throughout most of the various series.

In this matter, Sherlock Hound ${ }^{22}$ provides an interesting approach with regards to how animesque co-productions played a leading role in the promotion of anime aesthetics. Firstly, this is due to Hayao Miyazaki's highly recognizable style, openly regarded as very anime-like by European fandom and audiences $^{23}$. Secondly, this is due to the different timing in regards to the arrival and broadcasting of Miyazaki's 1978 series Future Boy Conan ${ }^{24}$. Future Boy Conan aired in Spain after 1990 through several regional broadcasters and was dubbed in co-official languages, in a similar fashion to Dragon Ball. Spanish viewers first came in contact with Miyazaki's style through Sherlock Hound, released in advance of Future Boy Conan despite being a later production. Consequently, when Miyazaki's early movies arrived in the nineties, they felt somehow familiar to many viewers who grew up with Sherlock Hound on TV, sharing many of Miyazaki's signature traits (currently identified as genuinely animesque by most European viewers).

Euro-Japanese animated co-productions were meant first and foremost for an European audience. Character designs, plots and general scenarios were usually distinct from other coetaneous anime series produced entirely in Japan. Thus, there are some shared traits that are usually identified as non-animesque, that is topics and themes, some of which refer to domestic referents, European literature and cultural traditions; the overall tone, with a more childish and infantile approach, meant for children, or lacking appeal for an older audience; an abundance of non-human protagonists, animals or anthropomorphous animals as characters (Dogtanian, Willy Fog, Maya the Bee, Sherlock Hound, Bannertail, etc.) However, when we address design, cinematography or rhythm ${ }^{25}$, many traces of the Japanese craftsmanship are still recognizable. Thus, I believe the animesque flair relies on several aspects involved in the production process.

\subsection{Narrative Continuity between Chapters}

Anime narratives present an abundance of self-contained series and self-contained stories, providing narrative continuity throughout different episodes, as compared to both self-conclusive or

22 Sherlock Hound (Meitantei Holmes, 1981) is a quite unique example of Euro-Japanese co-production and for that reason I will address it with great caution throughout this paper. Over time Sherlock Hound-a brilliant 1981 co-production between the Italian broadcasting conglomerate RAI and Tokyo Movie Shinsha-has achieved a cult status among fans and critics alike. Its animation exceeds both in quality and production details many other contemporary productions. Hayao Miyazaki was initially involved in the series, directing six chapters. However, production came to a hiatus due to a legal conflict with Conan Doyle's right-holders. When production restarted in 1984 Miyazaki was already immersed in his Nausicä̈ project. Kyosuke Mikuriya was responsible for the remaining 20 episodes. Despite this, Miyazaki's signature style is reflected throughout the whole series, in character's design, action sequences or humor scenes.

23 Despite Miyazaki's attempt to address his movies not as anime but as manga-eiga-an archaic term-and distance himself from the larger idea of the anime medium.

24 Mirai Shōnen Conan. NHK, 1978.

25 More than twenty different animated series were analyzed for the purpose of this research, categorized into three different groups: (1) US animated cartoons, popular among the Spanish audience in the 1980s; (2) Euro-Japanese co-productions from the same period; and (3) several coetaneous anime series, many of which aired years later in Spain once the liberalization of the TV frequencies took place. 
self-contained chapters, more common in the analyzed US cartoons ${ }^{26}$. When it comes to Euro-Japanese co-productions, this same pattern appears to a greater or lesser degree. In most BRB International co-productions the story works as a whole, developed through the several episodes that comprise the complete series. Despite this, it is not unusual that some US productions ${ }^{27}$-quite famous and successful with Spanish children at that time-also provide a self-contained story; however, while chapters might be interrelated and provide a sense of continuity (not self-conclusive), they are self-contained, as they usually present, develop and conclude an episode-plot that is relevant to the overall-plot but does not rely on cliffhangers at the end of the chapter.

\subsection{Recurrent Use of Cliffhangers and Eucatastrophe}

This feature is closely connected with the previous item. In most of the analyzed anime series and Euro-Japanese co-productions, there is a generalization of the cliffhanger as a tool-for narrative purposes and in order to build up momentum. Moreover, many of these animesque series use eucatastrophe as an aid to loosen the tension delivered with the cliffhanger. Both resources, extremely common in anime series and Euro-Japanese co-productions, provide a different sense of rhythm.

\subsection{Iconic and Reductionist Character Designs and Conventionalized Elements}

In many of the anime series and BRB co-productions analyzed, character design is neither cartoony nor realistic but rather iconic, based on the suppression of superfluous elements. This is a quite simple and yet effective feature also common in manga. The character designs rely on a set of conventionalized elements (Suan 2015) which ultimately point to the idea of the animesque. We might not fully talk about Azuma (2009) database or Suan (2013) mosaic in Euro-Japanese co-productions, but many of the characters depicted in these series share common traits with their anime counterparts. Nonetheless, their facial expressions and bodily movements are closer to the conventionalized elements expected from the animesque, especially when it comes to human characters (as depicted in Ruy Little Cid) rather than anthropomorphic animals (as seen in Dogtanian). The way Ruy smiles, blushes or rolls his eyes is closer to animesque characters than to those from US or European animated productions in the mid-1980s-mostly when compared with the designs from the Meisaku collection series such as Heidi. Moreover, despite the anthropomorphic dogs portrayed in a Doyle's Victorian-steampunk scenario, Sherlock Hound uses the same set of conventionalized anime elements such as facial expressions and bodily movement. Furthermore, it uses Miyazaki's own conventionalized designs-which do not fully fall within Azuma's database or Tezuka's star-system.

\subsection{Specificity of Color Palette and Abundance of Tertiary Colors}

Many Euro-Japanese co-productions present a distinctive hand-drawn quality of the line and a particular color palette, with an abundance of tertiary colors and less saturated scenes, quite similar to the anime series being produced in the 1980s. Of course, these formal similarities are but the logical result of co-productions being crafted by Japanese studios. However, there are solid similarities between the Euro-Japanese co-productions and several coetaneous anime, especially when compared to mainstream American cartoons. In the aforementioned US-animated productions, there is a consistent color palette throughout the whole series-with minimum or non-existent color variations in characters-whereas anime deeply relies on a changing palette matching the equally variable range of emotions of the characters and environments in which the action takes place (Horno-López 2013, pp. 233-34). As stated by Horno-López, "colour can also become a key element that can act both as a shaping tool for the figure and as a narrative tool for animation itself" (Horno-López 2013, p. 229). Horno-López

26 E.g., He-man and the Masters of the Universe (Filmation, 1983), The Real Ghostbusters (Columbia Pictures and DiC Entertainment, 1986).

27 E.g., Dungeons and Dragons (Marvel Comics and TSR, 1983). 
further examines the potential ramifications of the "dynamic use of color" and the variations in color regardless of characters in some anime (Horno-López 2017, pp. 158-59). Without inferring such a sophisticated use of color in the analyzed animated Euro-Japanese co-productions of the 1980s, it is an equally identifying element nonetheless, especially with regard to the emotional representation of the characters (as seen in Ruy, Little Cid, Dogtanian and the Three Muskehounds) as opposed to the consistent color palette of the main protagonists in American cartoons-such as Dungeons and Dragons or the invariable color of the characters depicted in a pantone-like style in He-man and the Masters of the Universe. Ultimately, it is possible to speak of storytelling through color, that is, animesque productions do not necessarily display a realistic depiction of color, but instead an emotional representation of color to match both the overall atmosphere of different scenes and the iconicity of the characters.

\subsection{Volume through Movement}

There is a certain popular consensus regarding addressing anime as flat, often backed by concepts such as Murakami's superflat, coined by the artist in his superflat manifesto, as a result of an exhibition that took place in Tokyo in the year 2000. For Murakami, superflat is about blending styles, surfaces, images, literature, social references, into a 2D picture plane. Notwithstanding, both Lamarre (2009) expand the original concept of superflat in regards to selective animation (Gan 2008) ${ }^{28}$, "that produces a sense of dynamic movement on a flat plane rather than movement ( . . ) in depth" (Shamoon 2015, p. 94). As Lamarre states, "Murakami's account suggests that, if one is to think across media and between lineages, then one has to think about kinds of movement. He does not centre his account of flatness or two-dimensionality on movement per se. Yet his discussion invariably returns to, and turns on, the problem of movement" (Lamarre 2002, p. 334). Lamarre then adds: "I should like to stretch Murakami's superflat, and think of a superflat that entails flat interactions or flat articulations. That is, the superflat becomes a quality of movement, change or transformation" (Lamarre 2002, p. 338).

In the last decade, the expression 'selective animation' has been broadly used to address anime instead of the traditional definition of 'limited animation'. Although the Japanese studios first relied on limited animation due to budget constraints-especially when compared with the American animation industry-over time this limitation became its strength, leading to a series of unique aesthetic resources and the appearance of a sense of pace and rhythm that ultimately defined anime as we know it. The movement of cells and layers in multiple directions at different speeds creates a new sense of dynamism (Horno-López 2014, pp. 89-90). Thus, 'limited animation'—which has negative connotations-became 'selective animation' as a result of this creative shift.

However, from a simple material perspective, I would argue that anime is not necessarily flat (when understood as a lack of volume), and that this conception comes from a different understanding of how to create volume and movement in 2D animation ${ }^{29}$. In many of the analyzed US cartoons, movement is achieved by physically rendering the different frames of the characters, while 1980s anime and animesque productions rely deeply on stills and yet sometimes achieved a larger feeling of motion through a clever use of multi-planar, parallax effects and utterly unconventional montage. "Rather than attempting to mimetically reproduce movement in depth, Japanese animators have tended to emphasize sideways 2-D motion and a dynamic iconography" (Shamoon 2015, p. 94). In He-man and the Masters of the Universe, Dungeons and Dragons or The Real Ghostbusters, background and figure unfold on the same level, and while the characters are indeed animated, it ultimately provides a sense of flatness. Instead, in anime there is a fairly distinct graphic approach between background and figure. Anime

28 Selective animation as defined by Gan: "Selective Animation is a new term intended to replace the older expression "limited animation" (...) Such simplified expressions are common in Japan, as several generations have grown up with animated series on television where simplified expressions are standard. In addition, the international commercial success of anime in recent years has also increased their confidence that these expressions are effective, possessing a different aesthetic from the so-called full animation". (Gan 2008, pp. 6-7).

29 As pointed by Lamarre "Moreover, as a consequence of the emphasis on static images, camera effects became more pronounced - panning across images, following objects, tracking up or back, framing in or out" (Lamarre 2002, p. 336). 
and the Euro-Japanese co-productions define volume through movement; thus, instead of animating the characters themselves within a still frame, anime 'moves' the camera (the different still layers in the frame) providing a deeper sense of volume. As a result, this creative 'device' redefines the perception of rhythm.

\subsection{Particularities in Shots and Montage}

Finally, there are significant differences in shots and montage, which help to build an inner rhythm. I would like to pay further attention to this point.

Many of the aforementioned animated co-productions use multiple long shots to depict the scenario and environs in which the action is going to take place. For instance, if we take a close look at the opening scene of the first chapter of Dungeons and Dragons, He-man and the Masters of the Universe $^{30}$ or The Real Ghostbusters, we immediately realize there is only one long shot introducing the action preceding the appearance of the main protagonists (or other characters involved in the scene). Conversely, the opening scenes of many of the analyzed anime shows are composed of multiple shots, offering not only visual/objective information on the environment in which the action takes place but also sensitive/subjective information "most often used to establish a mood or a sense of place" (McCloud 1993, p. 79). In Future Boy Conan, the creators used eight different shots for the opening scene, while in both Heidi and Mazinger Z they used five. In a similar fashion, BRB International's co-productions depict an identical usage of multiple introductory shots with an ambience function (Figure 1). Thus, we could easily argue that this sense of rhythm—intentionally reveling in details-is a very recognizable trait of the animesque in many early Euro-Japanese co-productions.

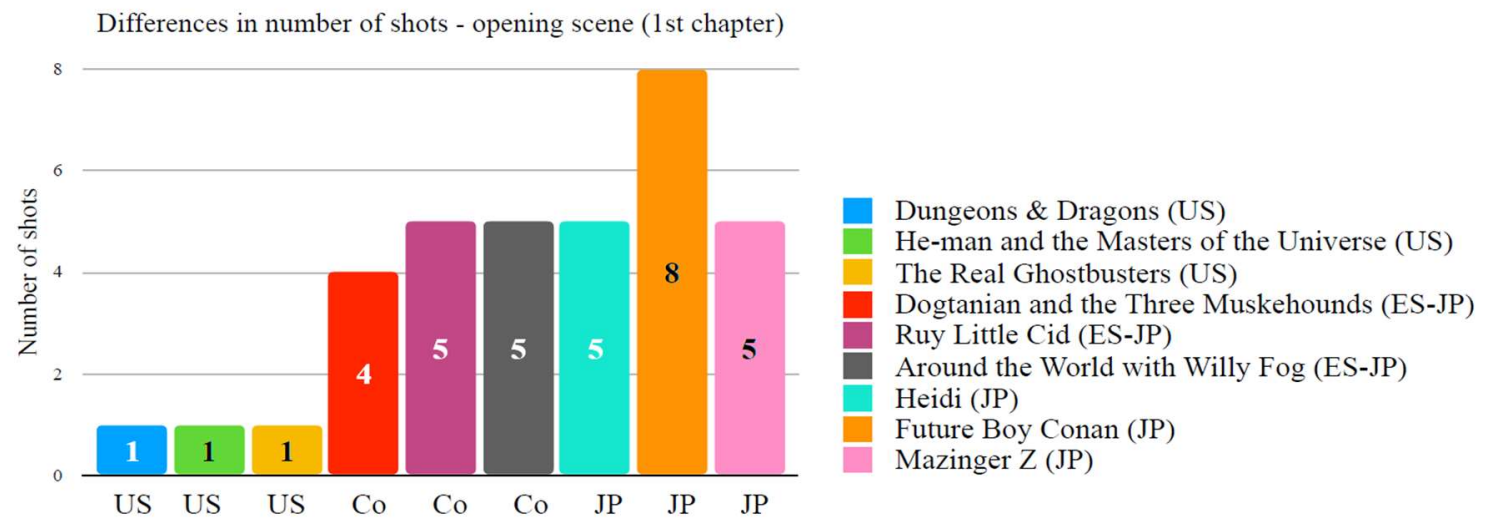

Figure 1. Comparative chart between some early 1980's American cartoons, Japanese anime series and animesque Euro-Japanese co-productions, according to the number of shots used in the first chapter's opening scene. Chart by author @2018 José Andrés Santiago Iglesias.

We observe a similar pattern with regard to the types of shots used in US cartoons, Japanese anime and Euro-Japanese co-productions aired in the 1980s. Again, when comparing the aforementioned US cartoons with anime from the late 1970s and early 1980s and BRB co-productions, the latter employ a large number of close-ups ${ }^{31}$. Hitherto many animated productions still relied on the structure and typical shots from the cinema industry. Thus, the analyzed US animated productions depict a more conservative montage, while the animesque rapidly jumps between different types of shots. In that regard, whether it was intended for economic reasons or creative motifs, anime's concatenation of shots became revolutionary in its own way. Furthermore, in regards to shots and montage, I firmly believe

30 Although the second shot might seem to be an independent shot, it is panning the camera to show us the room and the villains. Therefore, we can only refer to one introductory shot.

31 In Dungeons and Dragons, He-man and the Masters of the Universe or The Real Ghostbusters there are virtually no (or very few) close-ups, while both anime series and Euro-Japanese co-productions frequently use close-ups. 
that the correlation between anime and western animated productions is not unlike the interplay between manga and 1980s US mainstream comics. The connections between frames in manga-with the dominance of 'subject to subject', 'scene to scene' and especially 'aspect to aspect' as addressed by McCloud (1993, p. 74)—resemble the connections between shots in anime (a bond of sorts between komawari and montage). At the same time, the lack of close-ups in US cartoons is stressed by the fact that there are almost no non-human shots providing information about the environment. While anime and animesque co-productions usually use these kind of shots with metonymical intention, the analyzed US cartoons tend to focus exclusively on the characters, thus providing a more literal approach. These 'aspect to aspect' connections in montage are closely related to the pillow shot, as thoroughly analyzed by Shamoon (2011). Thus, as it happens with some 'aspect to aspect' connections, the pillow shot has symbolic value but does not necessarily move the plot forward. Despite this, the pillow shot is a less abundant resource in these early co-productions than in contemporary anime. Aimed at a children's audience, these animesque series were far less sophisticated than contemporary an anime ime both in terms of technical development and montage.

Sherlock Hound indeed uses the pillow shot as well as other animetic resources, but it does so in a very particular way, as it deeply relies on Miyazaki's unique shots and signature moves, hardly seen in any US-animated cartoons in the 1980s. Lamarre already acknowledges Miyazaki's uniqueness in this regard: "in many respects, Miyazaki appears to be the least animetic and most cinematic of animator-writer-directors" (Lamarre 2002, p. 341). For instance, to provide a deeper sense of movement and make it feel cinematic, Sherlock Hound uses a lot of in-depth camera movements. One of Miyazaki's signature shots—seen in most of his early works and frequently used in Sherlock Hound-comes as a result of his collaboration with animator Yasuo Ōtsuka who is mainly remembered for using the 'peg hole' technique. By rotating the still (genga) around the hole at the top of the animation sheet (the peg $b a r$, and thus the name of the technique), Miyazaki and Ōtsuka set a unique feeling of unbalance. Thus, Miyazaki's frenzy runners would oscillate into and out of the motion-barely keeping their equilibrium—instead of running in a straight line towards the camera.

\section{A Bridge for Anime: Conclusions}

Appealing to a European audience, Euro-Japanese animated co-productions lacked some recognizable features associated with anime as a larger medium. Themes, plots and scenarios were vastly distinct from mainstream anime series. Nonetheless, in many of these animated productions there was an underlying animesque flair in the shape of the conventionalized elements, character design, facial expressions, tropes, rhythm, camera-action, shots and montage. After European audiences had first contact with anime in the late 1970s, animated co-productions between domestic producers and Japanese studios emerged in the early 1980s, playing a leading role in the standardization of anime aesthetics, and hence contributing to a broader development of anime in Spain and other major European markets. Actually, these pioneering co-productions favored the arrival of Japanese studios and anime licenses to the European broadcasting scenario. We cannot refer to it as domestication, since these animated series were already 'domestic' products. However, we might speak of a passive acquisition of anime's aesthetics and most relevant visual elements. There was an unconscious osmosis of sorts from the anime's substratum, coding it within a whole generation of viewers and providing the tools (basic tools but tools nevertheless) to decode anime. Ultimately, I believe Euro-Japanese co-productions laid the foundations for what animesque means in Spain and how viewers approach anime as a medium.

Funding: This research received no external funding.

Conflicts of Interest: The author declares no conflict of interest.

\section{References}

Azuma, Hiroki. 2009. Otaku: Japan's Database Animals. Minneapolis: University of Minnesota Press. 
Berndt, Jaqueline. 2012. Facing the Nuclear Issue in a "Mangaesque" Way: The Barefoot Gen Anime. Cinergie 2: 148-162.

Fernández, Benito. 1978. Análisis de un mito Televisivo «Mazinger Z», un Robot que Influye en sus Hijos. ABC. July 8. Available online: http:/ / hemeroteca.sevilla.abc.es/nav/Navigate.exe/hemeroteca/sevilla/abc. sevilla/1978/07/08/033.html (accessed on 3 June 2018).

Gan, Sheuo Hui. 2008. The newly developed form of Ganime and its relation to selective animation for adults in Japan. Animation Studies 3: 6-17.

Horno-López, Antonio. 2013. Animación Japonesa. Análisis de Series de anime Actuales. Ph.D. thesis, Universidad de Granada, Granada, Spain.

Horno-López, Antonio. 2014. El arte de la animación selectiva en las series de anime contemporáneas. In Con A de Animación. Valencia: Universidad Politécnica de Valencia, vol. 4.

Horno-López, Antonio. 2017. El Lenguaje del Anime. Del Papel a la Pantalla. Madrid: Diábolo Ediciones.

Lamarre, Thomas. 2002. From animation to anime: Drawing movements and moving drawings. Japan Forum 14: 329-67. [CrossRef]

Lamarre, Thomas. 2009. The Anime Machine: A Media Theory of Animation. Minneapolis and London: University of Minnesota Press.

McCloud, Scott. 1993. Understanding Comics: The Invisible Art. New York: HarperCollins.

Moliné, Alfons. 2002. El Gran Libro de los Manga. Barcelona: Ediciones Glénat S.L.

Montero, Laura. 2012. Una Conquista Inversa: La Importancia del Anime en el Mercado del Manga Español. Puertas a la Lectura 24: 44-57.

Ortega, Juan Manuel. 1978. La Televisión Como Escuela de Violencia. Madrid: ABC, October 15.

Pellitteri, Marco. 2008. Mazinga Nostalgia. Storia, Valori e Linguaggi Della Goldrake-Generation 1978-1999. Roma: Coniglio Editore.

Pellitteri, Marco. 2010. The Dragon and the Dazzle: Models, Strategies and Identities of Japanese Imagination. Latina: Tunué Editori dell'imaginario.

Querol, Jordi. 2011. MundoManga (ZN Recomienda): Mazinger Z, la Enciclopedia, Tomo 1: Ni una piedra sin analizar [online]. Zona Negativa. March 23. Available online: http:/ / www.zonanegativa.com/mundomangazn-recomienda-mazinger-z-la-enciclopedia-tomo-1-ni-una-piedra-sin-analizar/ (accessed on 6 June 2018).

Romero, Jesús. 2014. ¡Mazinger. Planeador abajo! Palma de Mallorca: Dolmen.

RTVE. 2014. Esto Me Suena. Las Tardes del Ciudadano García-'Mazinger Z', un Hito Generacional. March 21. Available online: http:/ / www.rtve.es/alacarta/audios/esto-me-suena-las-tardes-del-ciudadano-garcia/ esto-suena-tardes-del-ciudadano-garcia-mazinger-z-hito-generacional/2461131/ (accessed on 23 June 2016).

Santiago, José Andrés. 2017. Dragon Ball popularity in Spain compared to current delocalized models of consumption. How Dragon Ball developed from a regionally-based complex system into a nationwide social phenomenon. Mutual Images Journal 2: 110-36.

Sanz-Arranz, J. Aurelio. 2011. Mazinger Z. La enciclopedia. Palma de Mallorca: Dolmen Editorial.

Shamoon, Deborah. 2011. The Films on Paper: Cinematic Narrative in Gekiga. In Mangatopia. Essays on Manga and Anime in the Modern World. Edited by T. Perper and Martha Cornog. Oxford: Libraries Unlimited, pp. 21-36.

Shamoon, Deborah. 2015. The Superflat Space of Japanese Anime. In Asian Cinema and the Use of Space: Interdisciplinary. Edited by Lilian Chee and Edna Lim. London: Routledge.

Suan, Stevie. 2013. The Anime Paradox: Patterns and Practices through the Lens of Traditional Japanese Theater. Leiden and Boston: Global Oriental.

Suan, Stevie. 2015. Performing differently: Convention, medium, and globality from manga (studies) to anime (studies). In Comicology: Probing Practical Scholarship. Edited by Jaqueline Berndt. Kyoto: Kyoto International Manga Museum.

Suan, Stevie. 2017. Anime's Performativity: Diversity through Conventionality in a Global Media-Form. Animation. An Interdisciplinary Journal 12: 63. [CrossRef]

Variety. 1984. Spain: Spanish Animator Uses Japan Shops. Variety, April 18, 206.

(C) 2018 by the author. Licensee MDPI, Basel, Switzerland. This article is an open access article distributed under the terms and conditions of the Creative Commons Attribution (CC BY) license (http://creativecommons.org/licenses/by/4.0/). 